\title{
A 0.45 W 18\% PAE E-Band Power Amplifier in 100 nm InGaAs pHEMT Technology
}

\author{
Dixian Zhao iD and Yongran Yi \\ National Mobile Communication Research Laboratory, School of Information Science and Engineering, Southeast University, \\ Nanjing 211189, China \\ Correspondence should be addressed to Dixian Zhao; dixian.zhao@seu.edu.cn
}

Received 21 October 2017; Revised 27 January 2018; Accepted 27 February 2018; Published 29 March 2018

Academic Editor: Enrico M. Vitucci

Copyright (C) 2018 Dixian Zhao and Yongran Yi. This is an open access article distributed under the Creative Commons Attribution License, which permits unrestricted use, distribution, and reproduction in any medium, provided the original work is properly cited.

\begin{abstract}
This paper describes a fully integrated power amplifier (PA) in $100 \mathrm{~nm}$ InGaAs pHEMT process for E-band point-to-point communications. The device size and biasing conditions are optimized to enhance the overall performance at millimeter-wave frequencies. The complete PA consists of two unit PAs and each unit PA has four stages to improve the gain while ensuring stability from dc to the operating frequencies. A 4-way zero-degree combiner (in the unit PA) and a 2-way $\lambda / 2$ combiner are used to boost the output power. Occupying $5 \mathrm{~mm}^{2}$, the proposed PA achieves an output power of $0.45 \mathrm{~W}$ with $17.9 \% \mathrm{PAE}$ at $74 \mathrm{GHz}$.
\end{abstract}

\section{Introduction}

There is an increasing need of E-band technology for future 5G network infrastructure, such as wireless backhaul. In wireless backhaul systems, highly directional antennas are employed at both transmitter and receiver sides to compensate for the path loss $[1,2]$. For example, FCC Part 101 Rules [3] require a minimum antenna gain of $43 \mathrm{dBi}$ to ensure the E-band radio equipment transmitting "pencil beams" to ease interference analysis and spatial coordination of links. Nevertheless, for a multi-Gbps link exceeding multikilometer distance, a watt-level power amplifier (PA) is required to ensure $99.99 \%$ weather availability worldwide $[1,2]$. Such output power $\left(P_{\mathrm{OUT}}\right)$ requirement assigns new task for the fully integrated power amplifiers (PAs) at millimeter-wave (mm-Wave) frequencies.

Although the ever-increasing speed of MOS transistors provides new opportunities to mm-Wave designers, the low breakdown voltage limits the output power of E-band CMOS PAs to about $0.1 \mathrm{~W}[2,4,5]$. The work in [6] demonstrated an E-band $\mathrm{SiGe}$ PA with $27.3 \mathrm{dBm} P_{\mathrm{OUT}}$, but it may suffer additional loss in the packaging due to the placement of the output pads at the center of the die. Therefore, wattlevel E-band PAs still remain in the domain of compound semiconductors. At E-band, GaN PAs [7] deliver more than
$1 \mathrm{~W} P_{\text {OUT }}$ due to the high breakdown voltage while InP PAs [6] achieve PAE as high as $40 \%$ thanks to the high $f_{T} / f_{\text {MAX }}$. Nevertheless, GaAs technology [8-10] has the advantages of relatively low cost, high yield, and easy foundry access, offering an attractive alternative for E-band applications.

In this paper, we report a fully integrated E-band PA in $100 \mathrm{~nm}$ InGaAs pHEMT technology. Circuit optimizations have been applied to active device, unit PA, layout floorplan, and power combining structures to enhance the gain, output power, efficiency, and stability. The proposed $5 \mathrm{~mm}^{2} \mathrm{PA}$ demonstrates a measured power gain of $20.6 \mathrm{~dB}$ and an output power of $26.5 \mathrm{dBm}$ with $17.9 \%$ PAE. Section 2 details the circuit optimizations regarding the transistor biasing, amplifier stage, and power combining structure. Section 3 shows the measurement results with the conclusion given in Section 4.

\section{Design Considerations and Circuit Implementation}

The power amplifier prototype was designed in a commercial $100 \mathrm{~nm}$ InGaAs pHEMT process $\left(f_{T} / f_{\text {MAX }}=130 / 200 \mathrm{GHz}\right)$ with a breakdown voltage of $8 \mathrm{~V}$ and saturated output power density of about $600 \mathrm{~mW} / \mathrm{mm}$ at a normal supply voltage of $4 \mathrm{~V}$. The wafer thickness is $50 \mu \mathrm{m}$. In this work, the PA 


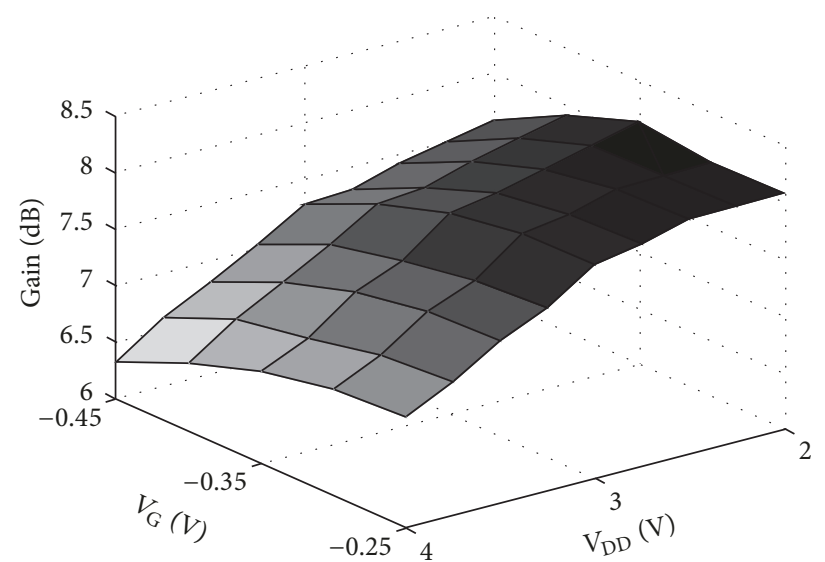

(a)

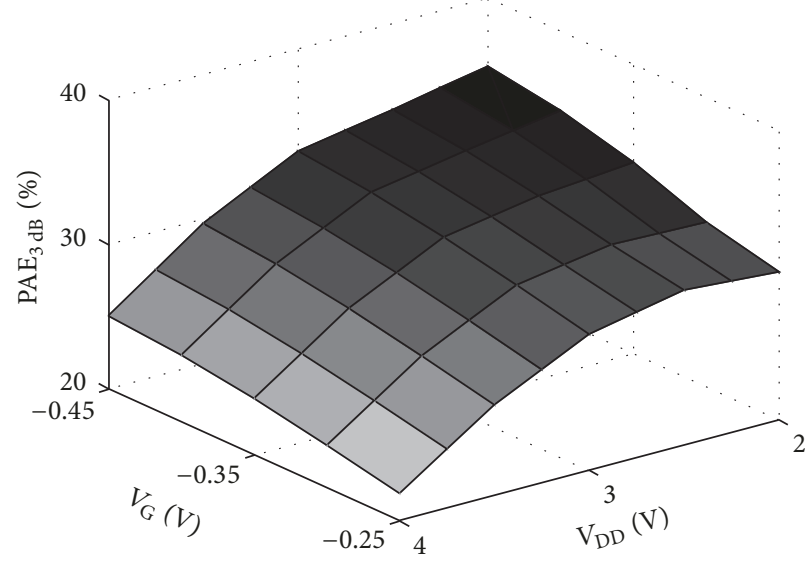

(c)

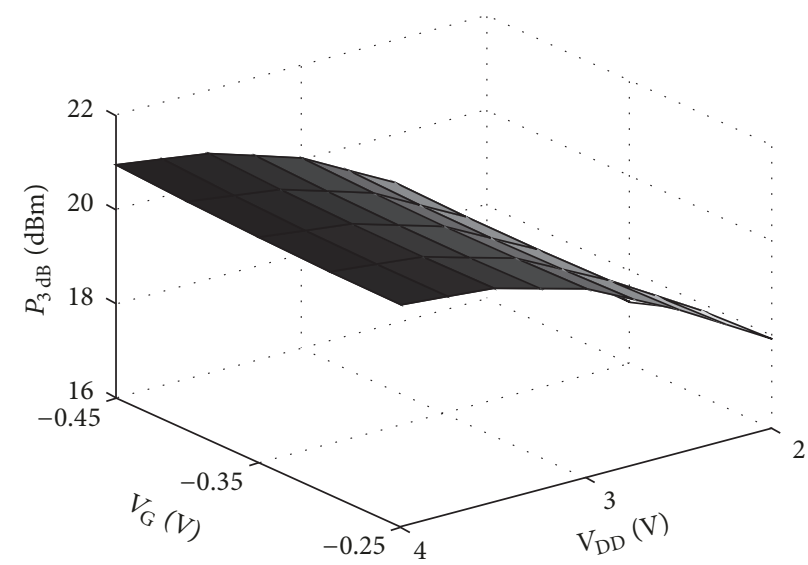

(b)

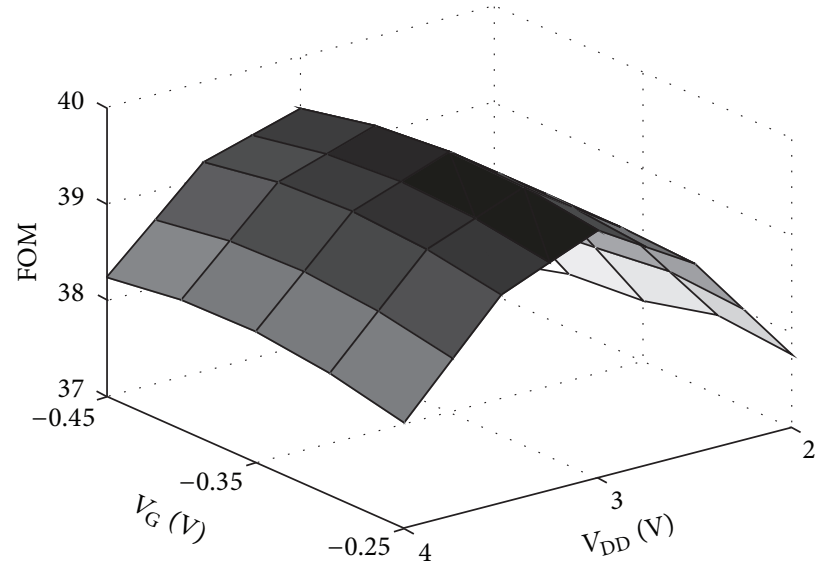

(d)

FIGURE 1: Single-stage PA metrics versus transistor biasing at $75 \mathrm{GHz}$ : (a) gain, (b) $P_{3 \mathrm{~dB}}$, (c) $\mathrm{PAE}_{3 \mathrm{~dB}}$, and $(\mathrm{d}) \mathrm{FOM}=\mathrm{Gain}(\mathrm{dB})+P_{3 \mathrm{~dB}}(\mathrm{dBm})+$ $10 \log \left[\mathrm{PAE}_{3 \mathrm{~dB}}(\%)\right]$.

simulations were performed in ADS based on the PDK models while all the passive devices were characterized with ADS momentum.

2.1. Transistor Design: Optimum Biasing. In this work, the transistor's biasing voltages are optimized based on the following PA figure-of-merit (FOM), given by

$$
\begin{aligned}
\mathrm{FOM}= & \text { Gain }(\mathrm{dB})+P_{3 \mathrm{~dB}}(\mathrm{dBm}) \\
& +10 \log \left[\mathrm{PAE}_{3 \mathrm{~dB}}(\%)\right],
\end{aligned}
$$

where gain, $P_{3 \mathrm{~dB}}$, and $\mathrm{PAE}_{3 \mathrm{~dB}}$ represent the power gain under power match, the $3 \mathrm{~dB}$ compressed output power $\left(P_{3 \mathrm{~dB}}\right)$, and the PAE at $P_{3 \mathrm{~dB}}\left(\mathrm{PAE}_{3 \mathrm{~dB}}\right)$, respectively. Figure 1 shows the simulated power gain, $P_{3 \mathrm{~dB}}, \mathrm{PAE}_{3 \mathrm{~dB}}$, and the calculated FOM versus different gate voltage $\left(V_{\mathrm{G}}\right)$ and drain voltage $\left(V_{\mathrm{DD}}\right)$ at $75 \mathrm{GHz}$. In the design, the device size of $50 \mu \mathrm{m} \times 4$ (i.e., $50 \mu \mathrm{m}$ finger width, four fingers) is selected to balance the power gain and output power. The ideal lossless input and output matching circuits are retuned for each biasing condition for fair comparison. From Figure 1, it is obvious that the PA has increased gain at a supply voltage of $2 \mathrm{~V}$ and it shows enhanced output power at $4 \mathrm{~V}$. As the PA operates at a large fraction of $f_{T} / f_{\mathrm{MAX}}$, the limited power gain has a direct impact on the PAE. As a result, $\mathrm{PAE}_{3 \mathrm{~dB}}$ peaks at $V_{\mathrm{DD}}$ of $2 \mathrm{~V}$ and $V_{\mathrm{G}}$ of $-0.45 \mathrm{~V}$ despite the fact that the PA achieves $2 \mathrm{~dB}$ more $P_{3 \mathrm{~dB}}$ at $V_{\mathrm{DD}}$ of $4 \mathrm{~V}$. Such issue becomes even severe after including the loss of matching circuits. In this design, we chose the biasing points based on the FOM which equals the sum of the power gain, $P_{3 \mathrm{~dB}}$, and $\mathrm{PAE}_{3 \mathrm{~dB}}$. Figure $1(\mathrm{~d})$ shows that the FOM peaks at $V_{\mathrm{DD}}$ of $3 \mathrm{~V}$ and $V_{\mathrm{G}}$ of $-0.35 \mathrm{~V}$, giving the power gain, $P_{3 \mathrm{~dB}}$, and $\mathrm{PAE}_{3 \mathrm{~dB}}$ of $7.8 \mathrm{~dB}, 19.5 \mathrm{dBm}$, and $31.6 \%$, respectively, at $75 \mathrm{GHz}$.

Besides, an important feature for the $50 \times 4 \mu \mathrm{m}$ transistor under such biasing configuration is that the gain match and power match can be nearly achieved simultaneously, which significantly reduces the design efforts. Note that though $25 \times$ $4 \mu \mathrm{m}$ transistor shows relatively high maximum small-signal gain, it is potentially unstable at E-band and shows $3 \mathrm{~dB}$ lower $P_{\text {OUT }}$ than $50 \mu \mathrm{m}$ one which will complicate the power combining network for the same $P_{\text {OUT }}$ requirement.

2.2. Unit PA Design: Gain, Power, and Stability. Using the optimum device size and bias configurations, a fully integrated unit PA is designed, as shown in Figure 2, where the 


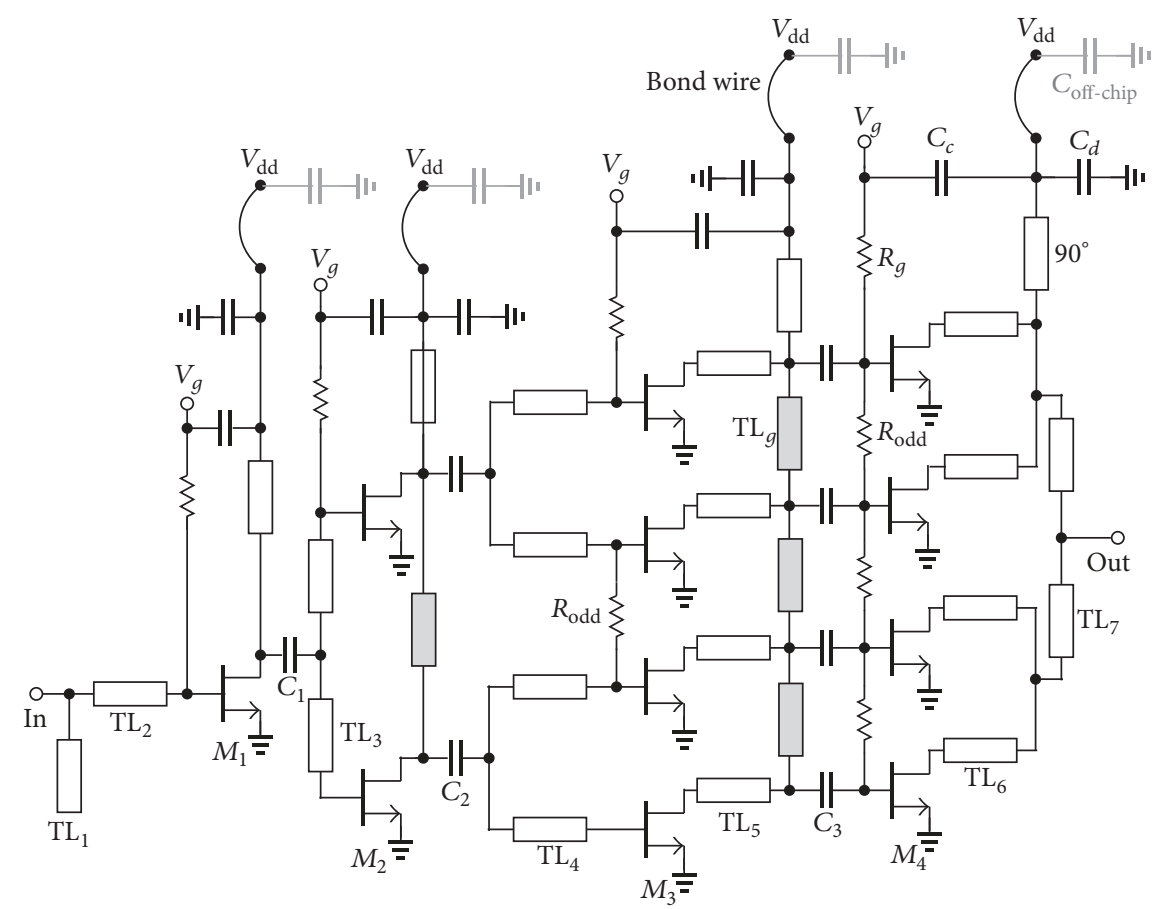

\begin{tabular}{lcccccc}
\hline$M_{1}$ & $M_{2}$ & $M_{3}$ & $M_{4}$ & $C_{1}$ & $C_{2}$ & $C_{3}$ \\
\hline $50 \mu \mathrm{m} \times 2$ & $50 \mu \mathrm{m} \times 2$ & $50 \mu \mathrm{m} \times 2$ & $50 \mu \mathrm{m} \times 4$ & $46 \mathrm{fF}$ & $80 \mathrm{fF}$ & $87 \mathrm{fF}$ \\
\hline $\mathrm{TL}_{1}$ & $\mathrm{TL}_{2}$ & $\mathrm{TL}_{3}$ & $\mathrm{TL}_{4}$ & $\mathrm{TL}_{5}$ & $\mathrm{TL}_{6}$ & $\mathrm{TL}_{7}$ \\
\hline $36 \Omega, 48^{\circ}$ & $36 \Omega, 26^{\circ}$ & $95 \Omega, 32^{\circ}$ & $65 \Omega, 15^{\circ}$ & $95 \Omega, 12^{\circ}$ & $36 \Omega, 40^{\circ}$ & $30 \Omega, 25^{\circ}$ \\
\hline
\end{tabular}

FIgURE 2: Simplified schematic of the E-band unit power amplifier.

details of the device parameters are also summarized. The unit PA consists of four stages to achieve more than $20 \mathrm{~dB}$ power gain and thus relax the input power requirement. To provide sufficient driving power and in order not to saturate prior to the output stage, the total transistor width of three driver stages is scaled down by a factor of two progressively. A 4-way zero-degree transmission-line (T-line) combiner [11] is employed to sum up $P_{\text {OUT }}$ of the four $50 \mu \mathrm{m} \times 4$ devices in the PA output stage. Compared to Wilkinson combiner, the zero-degree combiner significantly reduces the chip area and insertion loss while transforming the $100 \Omega$ load to the optimum load impedance of each $50 \mu \mathrm{m} \times 4$ device. The port isolation is not a major constraint here as all the combiner inputs have no phase difference. The $350 \mu \mathrm{m}$ $\lambda / 4$ T-lines are used as RF choke to feed the supply and the T-lines in grey $\left(\mathrm{TL}_{q}\right)$ are used to distribute the supply networks for the amplifier stages at lower side. Both $\mathrm{TL}_{g}$ and $R_{\text {odd }}$ (see Figure 2) can help to reduce the gain of internal loops and thus eliminate potential oscillations. The capacitor $C_{d}$ provides a short to ground in the range of operating frequencies. Extensive EM simulations have been performed on the complete passive circuits to take into account the mutual couplings between all the passive components. The simulated $P_{5 \mathrm{~dB}}$ and $\mathrm{PAE}_{5 \mathrm{~dB}}$ for the unit PA equal $24.9 \mathrm{dBm}$ and $22 \%$, respectively. Note that, at $P_{5 \mathrm{~dB}}$, the PA output stage is compressed by roughly $3 \mathrm{~dB}$ while the three driver stages are compressed by $2 \mathrm{~dB}$. As the power gains of both driver stages and output stage are very limited, such design methodology ensures that the PA output stage can be driven into saturation while three driver stages consume relatively low dc power [12].

As the transistor has much higher power gain at low frequencies, the stability there becomes a big concern. Simulation predicts that the unit PA is potentially unstable in the range of $25 \mathrm{GHz}$. To tackle this, $C_{c}$ is introduced at each stage to close the loop and thereby significantly reduce the power gain at low frequencies where the $\lambda / 4 \mathrm{dc}$-feeding $\mathrm{T}$-lines show relatively low impedance and $C_{d}$ shows high impedance. Consequently, the unit PA is unconditionally stable from $\mathrm{dc}$ to the operating frequencies and the in-band performance is not degraded at all.

2.3. Power Enhancement: Half-Wavelength T-Line Combiner. To further enhance the output power, the complete PA combines $P_{\text {OUT }}$ of two unit PAs using $\lambda / 2$ T-line power combiner, shown in Figure 3. A characteristic impedance $\left(Z_{o}\right)$ of $70 \Omega$ is chosen to balance the insertion loss and bandwidth. In this case, compared to Wilkinson and zero-degree combiners [11], the $\lambda / 2$ T-line combiner is compact and straightforward to implement and has relatively broad bandwidth. More importantly, it is not sensitive to the process variations while covering a distance as long as $700 \mu \mathrm{m}$ between the outputs of the two unit PAs. Including output GSG pads, the insertion loss of the $\lambda / 2 \mathrm{~T}$-line combiner is $0.68-0.71 \mathrm{~dB}$ at $75 \mathrm{GHz}$ for 


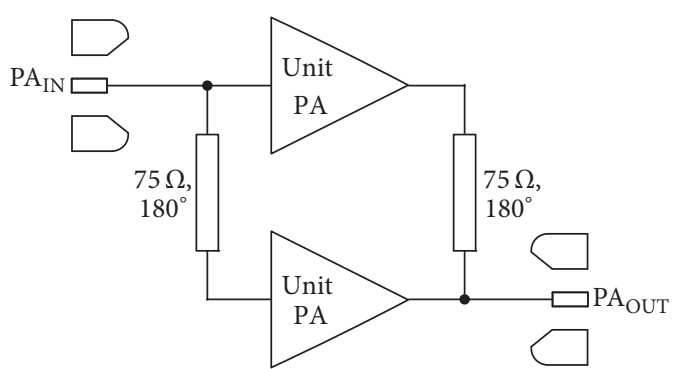

FIGURE 3: Power splitting and combining topologies based on $\lambda / 2$ T-lines.

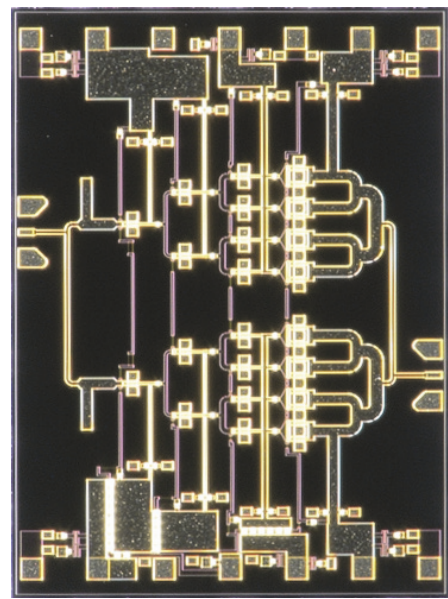

FIGURE 4: Chip micrograph.

a $\pm 20 \%$ variation in $Z_{o}$. To compensate $180^{\circ}$ phase difference, a $\lambda / 2$ T-line power divider is used at the input.

\section{Measurement Results}

The PA prototype is fabricated in a $100 \mathrm{~nm}$ InGaAs pHEMT process. The chip micrograph is shown in Figure 4. Including $\mathrm{RF}$ and dc pads, the chip occupies an area of $5 \mathrm{~mm}^{2}$. Measurements are performed on a high-frequency probe station. The input and output RF pads are accessed by GSG probes while dc pads are wire-bonded to a PCB. The supply voltage for the PA is $3 \mathrm{~V}$.

Figure 5 shows the measured S-parameters. The PA achieves a peak $S_{21}$ of $20.8 \mathrm{~dB}$ at $74 \mathrm{GHz}$ with the $3 \mathrm{~dB}$ bandwidth of $7.5 \mathrm{GHz}$. Thanks to the optimum transistor sizing and biasing, ensuring simultaneous gain match and power match, $S_{22}$ is better than $-10 \mathrm{~dB}$ from 71.5 to $78.5 \mathrm{GHz}$. $S_{11}$ is better than $-10 \mathrm{~dB}$ from 71 to $77 \mathrm{GHz}$ while $S_{12}$ is smaller than $-48 \mathrm{~dB}$ from 60 to $90 \mathrm{GHz}$. The PA is unconditionally stable in the measured frequencies. In addition, the output spectrum is carefully checked from dc to $90 \mathrm{GHz}$ and no oscillation appears at the PA output. The large-signal behavior of the PA at $74 \mathrm{GHz}$ is shown in Figure 6. The PA achieves a measured $P_{1 \mathrm{~dB}}, P_{3 \mathrm{~dB}}$, and $P_{5 \mathrm{~dB}}$ of $23.8,25.5$, and $26.5 \mathrm{dBm}$, respectively. $\mathrm{PAE}_{5 \mathrm{~dB}}$ is $17.9 \%$. From 71 to $79 \mathrm{GHz}$, the measured output power is more than $25 \mathrm{dBm}$ (see Figure 5). The measured and simulated results are in good agreement.

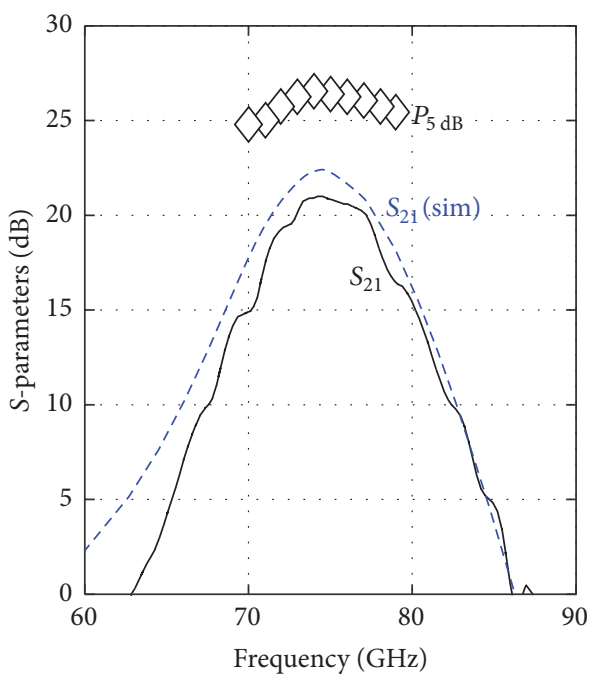

(a)

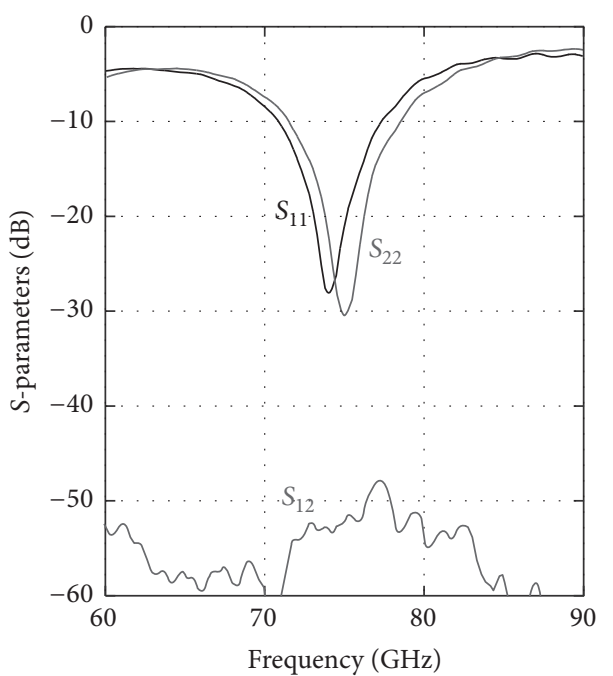

(b)

FIGURE 5: (a) Measured $S_{21}, P_{5 \mathrm{~dB}}$, and simulated $S_{21}$; (b) measured $S_{11}, S_{12}$, and $S_{22}$.

The $2 \mathrm{~dB}$ difference in gain can be attributed to the process variation and mutual couplings between multiple stages. The inaccurate modelling of back vias could be another issue as ADS momentum is a $2.5 \mathrm{D}$ electromagnetic (EM) simulator.

Table 1 compares the PA prototype to the state-of-the-art E-band PAs in GaAs, InP, SiGe, and CMOS. Albeit different technologies used, it can be seen that high output power will lead to relatively low efficiency owing to the loss in the power combining network. The work [6] in $250 \mathrm{~nm} \mathrm{InP}$ with $f_{T} / f_{\text {MAX }}$ of $400 / 700 \mathrm{GHz}$ shows an impressive PAE. Thanks to the proposed design techniques, this PA achieves both high output power and high efficiency in $100 \mathrm{~nm}$ InGaAs pHEMT, competing well with prior-arts at E-band.

\section{Conclusion}

An E-band PA has been implemented in $100 \mathrm{~nm}$ InGaAs pHEMT process. To enhance the single-stage amplifier 
TABLE 1: Performance summary and comparison.

\begin{tabular}{|c|c|c|c|c|c|c|}
\hline & Technology & $V_{\mathrm{DD}}(\mathrm{V})$ & Frequency $(\mathrm{GHz})$ & Gain $(\mathrm{dB})$ & $P_{5 \mathrm{~dB}}(\mathrm{dBm})$ & $\mathrm{PAE}_{5 \mathrm{~dB}}(\%)$ \\
\hline This work & $100 \mathrm{~nm} \mathrm{GaAs}$ & 3.0 & 74 & 20.8 & 26.5 & 17.9 \\
\hline [8] & $100 \mathrm{~nm} \mathrm{GaAs}$ & 4.0 & 83 & $15.0 / 18.7^{1}$ & $28.5 / 26.5^{1}$ & $\mathrm{~N} / \mathrm{A} / 15.0^{1}$ \\
\hline [9] & $100 \mathrm{~nm} \mathrm{GaAs}$ & 3.5 & 81 & 25.0 & $20.0^{2}$ & N/A \\
\hline [10] & $100 \mathrm{~nm} \mathrm{GaAs}$ & 4.0 & 76 & 15.0 & $23.0^{2}$ & $8.0^{2}$ \\
\hline [7] & 140 nm GaN & 14.0 & 93.5 & 16.3 & 33.3 & 19.0 \\
\hline$[13]$ & $250 \mathrm{~nm} \operatorname{InP}$ & 2.5 & 76 & 15.5 & 26.4 & 26.9 \\
\hline [14] & $250 \mathrm{~nm} \operatorname{InP}$ & 2.5 & 81 & 22.0 & 21.1 & 40.0 \\
\hline [6] & $90 \mathrm{~nm} \mathrm{SiGe}$ & 1.8 & 76 & 19.3 & $25.0^{3}$ & $9.0^{3}$ \\
\hline [15] & $130 \mathrm{~nm} \mathrm{SiGe}$ & 2.5 & 84 & 27.0 & $18.0^{2}$ & $9.0^{2}$ \\
\hline [2] & $40 \mathrm{~nm}$ CMOS & 0.9 & 78 & 18.1 & 20.3 & 22.3 \\
\hline [4] & $40 \mathrm{~nm}$ CMOS & 1.8 & 73 & 25.3 & 21.5 & 16.5 \\
\hline [5] & $65 \mathrm{~nm}$ CMOS & 1.0 & 79 & 24.2 & 19.0 & 18.5 \\
\hline
\end{tabular}

${ }^{1} P_{4 \mathrm{~dB}}$ and $\mathrm{PAE}_{4 \mathrm{~dB}} \cdot{ }^{2} P_{\mathrm{SAT}}$ and $\mathrm{PAE}_{\mathrm{SAT}} \cdot{ }^{3}$ Graphically estimated.

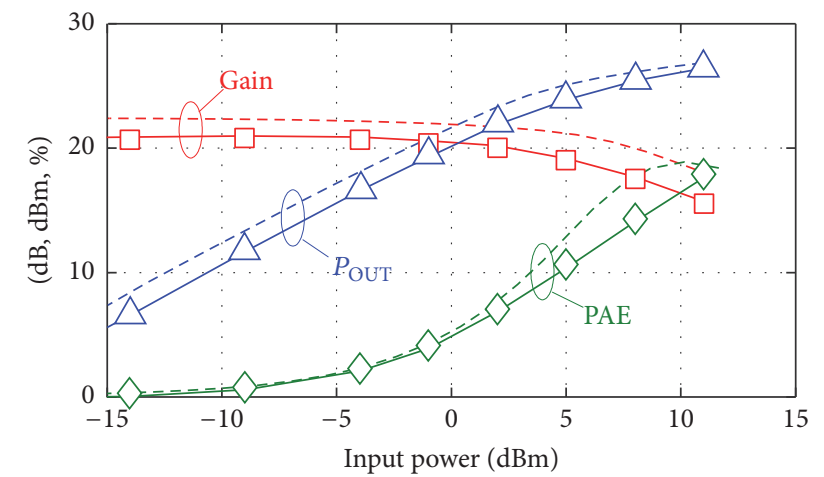

Figure 6: Measured and simulated (dashed) gain, output power, and PAE versus input power at $74 \mathrm{GHz}$.

performance, device size and biasing conditions are fine tuned. A 4-way zero-degree combiner and a 2-way $\lambda / 2$ combiner are used to improve the output power. Attention has been paid to the PA stability in order to ensure no oscillations appearing from dc to the operating frequencies. The $5 \mathrm{~mm}^{2}$ PA achieves an output power of $0.45 \mathrm{~W}$ with $17.9 \%$ PAE at $74 \mathrm{GHz}$. For future work, improvement can be done to reduce the insertion loss of the output combiner and thus further enhance the output power and efficiency. A highly efficient 16-way power combiner can also be investigated to double the output power. At E-band, the GaAs PA outperforms the CMOS PA regarding the output power while it achieves low cost, high yield, and easy foundry access when compared to InP and GaN PAs. Therefore, GaAs PA provides attractive solutions for future long-haul point-topoint communications at E-band.

\section{Conflicts of Interest}

The authors declare that they have no conflicts of interest.

\section{Acknowledgments}

This work is partly funded by the National Natural Science Foundation of China (no. 61674035), the Natural Science
Foundation of Jiangsu Province (no. BK20160690), and the Fundamental Research Funds for the Central Universities.

\section{References}

[1] J. Wells, Multigigabit Microwave and Millimeter-Wave Wireless Communications, Artech House, Norwood, MA, USA, 2010.

[2] D. Zhao and P. Reynaert, "An E-band power amplifier with broadband parallel-series power combiner in 40-nm CMOS," IEEE Transactions on Microwave Theory and Techniques, vol. 63, no. 2, pp. 683-690, 2015.

[3] FCC, "Fixed Microwave Services," https://www.ecfr.gov/cgibin/text-idx?SID=c7ae99179c50117778ff4dfb6787b0fc\&amp;mc= true\&amp;node=pt47.5.101\&amp;rgn=div5\#se47.5.101_1115.

[4] D. Zhao and P. Reynaert, "A 40-nm cmos E-band 4-way power amplifier with neutralized bootstrapped cascode amplifier and optimum passive circuits," IEEE Transactions on Microwave Theory and Techniques, vol. 63, no. 12, pp. 4083-4089, 2015.

[5] K.-Y. Wang, T.-Y. Chang, and C.-K. Wang, "A 1V 19.3dBm $79 \mathrm{GHz}$ power amplifier in 65nm CMOS," in Proceedings of the 59th International Solid-State Circuits Conference (ISSCC '12), pp. 260-261, February 2012.

[6] H.-C. Lin and G. M. Rebeiz, "A 70-80-GHz sige amplifier with peak output power of $27.3 \mathrm{dBm}$," IEEE Transactions on Microwave Theory and Techniques, vol. 64, no. 7, pp. 2039-2049, 2016.

[7] M. Micovic, A. Kurdoghlian, A. Margomenos et al., "92-96 $\mathrm{GHz}$ GaN power amplifiers," in Proceedings of the IEEE MTT-S International Microwave Symposium (IMS '12), Junuary 2012.

[8] E. Camargo, J. Schellenberg, L. Bui, and N. Estella, "Power GaAs MMICs for E-band communications applications," in Proceedings of the 2014 IEEE MTT-S International Microwave Symposium (IMS '14), June 2014.

[9] F. D. Canales and M. Abbasi, "A 75-90 GHz high linearity MMIC power amplifier with integrated output power detector," in Proceedings of the 2013 IEEE MTT-S International Microwave Symposium Digest (MTT '13), June 2013.

[10] M. C. Rodriguez, J. Tarazi, A. Dadello et al., "Full ETSI Eband doubler, quadrupler and $24 \mathrm{dBm}$ power amplifier," in Proceedings of the 2012 IEEE Compound Semiconductor Integrated Circuit Symposium (CSICS '12), October 2012. 
[11] W. Tai, L. R. Carley, and D. S. Ricketts, "A 0.7W fully integrated $42 \mathrm{GHz}$ power amplifier with $10 \%$ PAE in $0.13 \mu \mathrm{m} \mathrm{SiGe} \mathrm{BiC-}$ MOS," in Proceedings of the 2013 60th IEEE International SolidState Circuits Conference (ISSCC '13), pp. 142-143, February 2013.

[12] S. Cripps, RF Power Amplifier for Wireless Communications (Chapter 13.4 Multistage PA Design), Artech House, 2nd edition, 2006.

[13] Z. Griffith, M. Urteaga, P. Rowell, and R. Pierson, “340440mW Broadband, High-Efficiency E-Band PA's in InP HBT," in Proceedings of the 37th IEEE International Symposium on Workload Characterization, (CSICS '15), October 2015.

[14] Z. Griffith, M. Urteaga, P. Rowell, and R. Pierson, "71-95 GHz (23-40\% PAE) and 96-120 GHz (19-22\% PAE) high efficiency 100-130 mW power amplifiers in InP HBT,' in Proceedings of the 2016 IEEE MTT-S International Microwave Symposium (IMS '16), May 2016.

[15] Y. Zhao and J. R. Long, "A Wideband, dual-path, millimeterwave power amplifier with $20 \mathrm{dBm}$ output power and PAE above 15\% in $130 \mathrm{~nm}$ SiGe-BiCMOS," IEEE Journal of Solid-State Circuits, vol. 47, no. 9, pp. 1981-1997, 2012. 


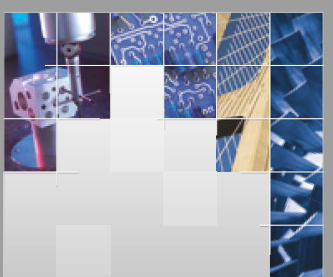

\section{Enfincering}
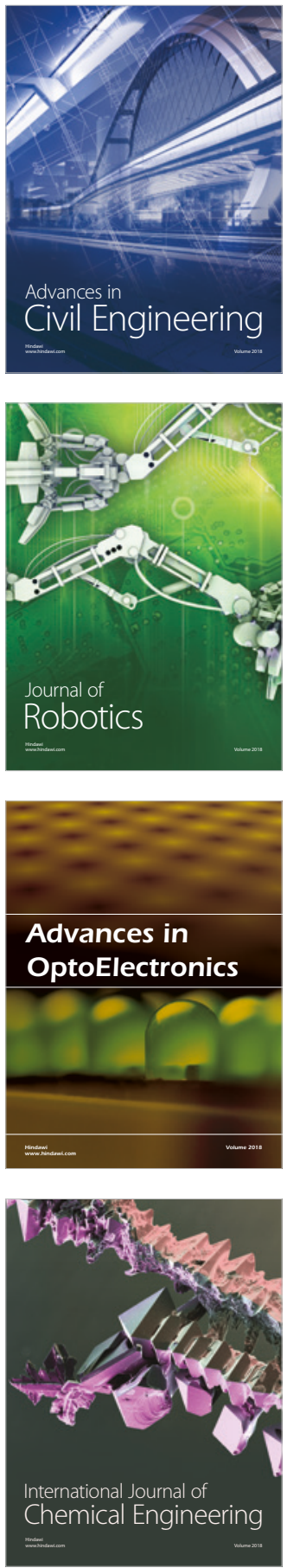

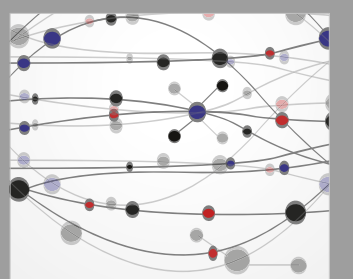

\section{Rotating \\ Machinery}

The Scientific World Journal

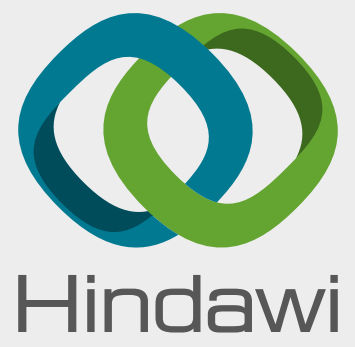

Submit your manuscripts at

www.hindawi.com
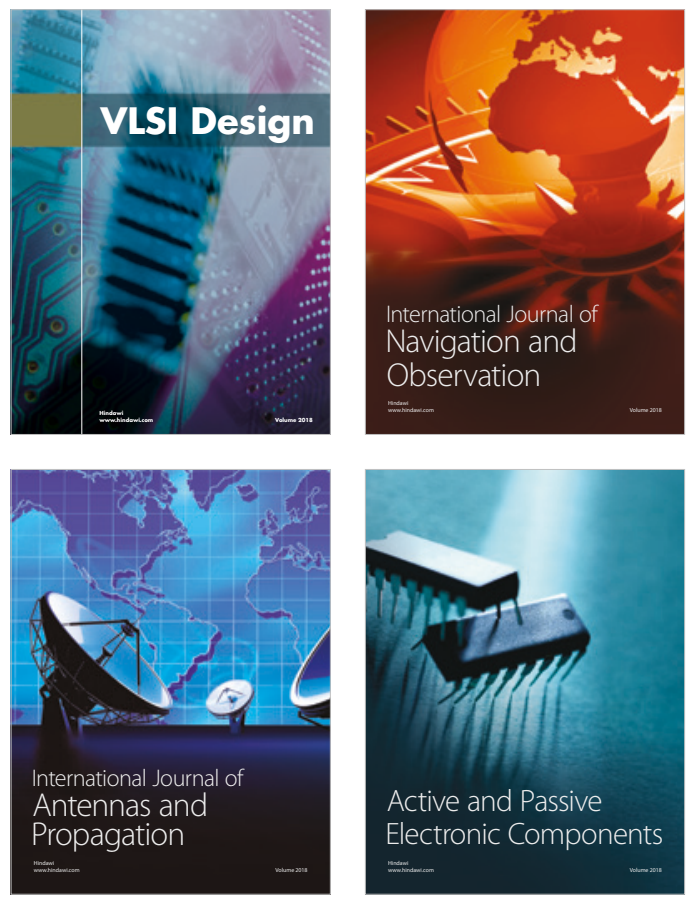
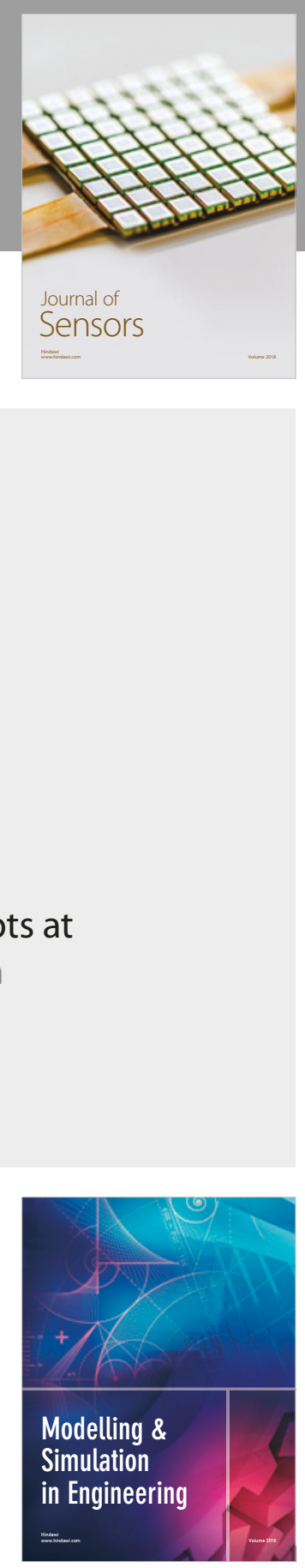

\section{Advances \\ Multimedia}
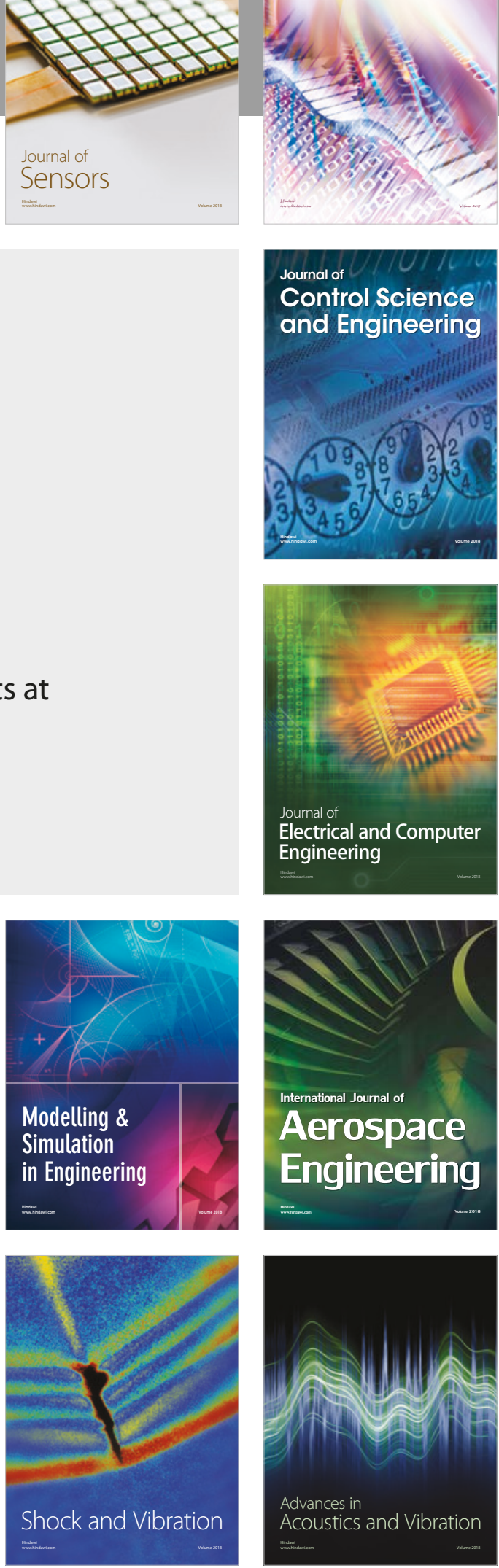